\title{
Модернізація системи охолодження магнетронів малої потужності
}

\author{
І. Л. Бочкова ${ }^{1 凶}$, А. С. Тітлов ${ }^{1}$, Н. В. Волгушева ${ }^{1}$, Н. О. Колесніченко ${ }^{2}$, T. А. Сагала ${ }^{1}$
}

${ }^{1}$ Одеська національна академія харчових технологій, вул. Канатна, 112, Одеса, 65039, Україна

${ }^{2}$ Військова академія, Фонтанська дорога, 10, Одеса, 65000, Україна

$\triangle$ e-mail: boshkova.irina@gmail.com

Розглядається питання забезпечення теплового режиму анодного блоку магнетрона шляхом заміни системи повітряного охолодження на систему рідинного охолодження. Стверджується, що система рідинного охолодження найбільш підходяща для магнетронів, які в даний час передбачають систему повітряного охолодження, однак не розраховані на тривалу роботу в складі промислових мікрохвильових установок. Організація системи рідинного охолодження дозволить магнетрон прачювати тривалий час без перегріву і в сприятливих умовах, при яких виключено забивання частинками і пилом поверхні теплообміну і виникнення перегріву поверхні анодного блоку. Основним елементом розроблюваної системи рідинного охолодження є сорочка охолодження, щуо представляє собою кільщевий канал з теплопровідного матеріалу. Сорочка охолодження кріпиться безпосередньо на анодний блок, при иььому ступінь стиснення поверхонь i товщина повітряного зазору повинні забезпечити мінімальне сумарне термічний опір. Для визначення коефіиієнтів тепловіддачі отримана емпірична залежність, яка відображає той факт, щуо при охолодженні анодного блоку рачіональними є в'язкі $i$ в'язкісно-гравітаџійні режими руху. Визначено основні теплові характеристики процесу охолодження, щу включають коефічієнт теплопередачі, зміну температури теплоносія, максимально допустиму температуру на вході. Розрахунки проведені для двох видів теплоносіїв: вода і 54 \% водний розчин етиленгліколю. Застосування даного схемного рімення $i$ вибір раціональних розрахункових режимних дозволяє вирішити проблему підвищення ефективності виробництва $i$ надійності роботи мікрохвильової техніки

Ключові слова: анодний блок, магнетрон, контактний термічний опір, вода, етиленгліколь, тепловий режим

\section{doi: https://doi.org/ 10.15673/ret.v55i3.1573}

\section{1. Вступ}

Існують особливості взаємодії мікрохвильового електромагнітного поля 3 полярними діелектриками, приміром, об'ємне нагрівання матеріалу й локальне нагрівання. Внаслідок цього мікрохвильова обробка здатна привести до нових ефектів і появи унікальних властивостей матеріалів $[1,2,3]$. Мікрохвильові технології привабливі тим, що дозволяють одержувати якісно нові матеріали, що неможливо досягти іншими методами термічної обробки. У зв'язку із цим зрозумілий інтерес до використання мікрохвильового нагрівання, що особливо сильно виявився останнім часом. Відповідно підсилився інтерес до конструювання промислових мікрохвильових пристроїв, що зв'язано зі значним здешевленням комплектуючих елементів для мікрохвильової техніки. Мікрохвильове (діелектричне) нагрівання 3 використанням енергії змінного електромагнітного поля мікрохвильового діапазону має перспективи використання в різних галузях промисловості $[4,5]$. Доцільність застосування мікрохвильового нагрівання обумовлені рядом показників, серед яких можна назвати [6]:

- можливість миттєвого керованого нагрівання або локального нагрівання;

- економія площ, що відводяться для зберігання, або встаткування, що випливає зі значного скорочення циклу обробки; 
- зменшення усушки й втрат у процесі обробки;

- більш висока якість оброблюваної продукції;

- значне зменшення теплових втрат у навколишне середовище й зниження і1і забруднення;

- висока бактерицидна дія мікрохвильової енергії;

- безінерційність нагрівання й можливість повної автоматизації процесу.

Однак впровадження мікрохвильових технологій гальмує те, що деякі важливі технічні питання не вирішені. До одному з таких питань ставиться проблема забезпечення теплового режиму генератора мікрохвильової енергіï. При цьому проблемі забезпечення теплового режиму магнетрона варто приділяти велику увагу, тому що при перевищенні температури поверхні анодного блоку вище припустимої генератор швидко виходить із ладу. Анодний блок - це основна частина магнетрона. Анодний блок складається 3 мідного циліндра, з порожнинами в центрі, які $є$ кільцевою системою об'ємних резонаторів. Електронний ККД магнетрона, що визначає ефективність перетворення енергії електронного потоку в енергію високочастотних коливань, досить високий (до $80 \%$ ), однак практично вся частина, що залишилася, виділяється у вигляді тепла на анодному блоці, викликаючи його розігрів. Для його охолодження на поверхні малопотужних магнетронів, які випускаються для мікрохвильових печей, установлюють ребристі радіатори. $€$ певний інтерес застосування таких магнетронів для промислових установок, для чого варто зробити систему охолодження більше надійної. Малопотужні магнетрони, що випускаються промисловістю, розраховані на побутові мікрохвильові печі. При використанні їх у промислових установок такі магнетрони часто перегріваються й виходять із ладу. При цьому доцільність їхнього використання пов'язана 3 тим, що вони досить надійні (при дотриманні теплових режимів) i значно дешевше магнетронів 3 високою вихідною потужністю. Крім того, рівномірний розподіл мікрохвильової енергії легше досягти застосуванням декількох магнетронів малої потужності, чим одного високопотужного. Проблема підтримки стійкого теплового режиму магнетронів 3 вихідною потужністю до 1 кВт при їхньому тривалому застосуванні в установках промислового призначення може бути вирішена за рахунок заміни системи повітряного охолодження (СПО) на систему рідинного охолодження (СРО). При цьому необхідна заміна ребер, установлених на анодному блоці, на сорочку охолодження, щільно підігнаної до поверхні анода. Перехід на СРО повинен супроводжуватися тепловими конструкторськими розрахунками, результатом яких є визначення робочих параметрів системи. Актуальність роботи пов'язана 3 тим, що модернізація системи забезпечення теплових режимів (СЗТР) магнетронів, що випускаються, дотепер не проводилася, що гальмує конструювання промислових мікрохвильових пристроїв. Метою дослідження $\epsilon$ аналітичне вивчення функціонування рідинної системи охолодження анодного блоку магнетрона 3 вихідною потужністю 1,0 кВт.

\section{2. Вивчення питання забезпечення теплового режиму роботи магнетронів}

У роботі [7] запропонований метод модифікації системи охолодження серійних магнетронів, що використовуються у побутовій і промисловій мікрохвильовій печах. Модифікація полягає в переході з повітряної системи охолодження на водяну. Показано, що рідинне охолодження може бути організовано навивкою тонкостінної мідної трубки безпосередньо на корпус приладу або установкою водяного радіатора у вигляді моноблока. Однак не наведені результати теплових розрахунків розроблювальних систем. Без надійних залежностей, які дозволяють оцінити режимні параметри роботи СРО, конструювання не буде завершеним. Питання конструювання й спряженості частин мікрохвильових пристроїв викладені в [8]. Представлені дані дозволяють установити фундаментальні концепції конструювання мікрохвильових пристроїв. Однак системам охолодження і їхньої модернізації приділяється недостатньо уваги. В [9] розглядаються особливості перетворення електричної енергії в енергію мікрохвильового поля й результати моделювання частотних характеристик магнетронів у безперервному режимі. Дослідження частотних характеристик магнетронів $\mathrm{i}$ їхній аналіз показує, що флуктуація частоти в магнетронних генераторах в'язана 3 електроннохвильовим механізмом взаємодії, режимом роботи приладу, умовами й особливостями його експлуатації й інших факторів. Це підкреслює важливість застосування надійної системи забезпечення теплового режиму магнетрона. При 
відхиленні від вимог до підтримки температури анодного блоку зрушується робоча точка магнетрона по вихідній частоті. Зрушення робочої точки приводить до погіршення ефективності роботи магнетрона як джерела енергії. Крім того, при перегріві зменшується термін служби магнетрона.

Важливість розробки надійної СЗТР відзначається в [10]. Вказується, що вплив зміни температури на надійність апаратури проявляється, по-перше, у зміні (оборотній і необоротній) електричних параметрів і характеристик виробів, по-друге, у залежності показників надійності виробів від температури. Одним з головних етапів проектування, що визначає напрямок всієї розробки системи забезпечення теплових режимів (СЗТР), є вибір способу охолодження магнетронів [11]. Представлено результати експериментальних досліджень можливої нестабільності частоти в магнетронах, включаючи результати дослідження впливу температури анодного блоку на частоту генерації. Установлено, що підвищення температури анодного блоку від 20 до $60{ }^{\circ} \mathrm{C}$ приводить до зниження частоти генерації магнетрона на $0,1 \%$. Стабілізація температури анодного блоку сприяе до стабілізації частоти. Дослідження системи охолодження малопотужного магнетрона 3 використанням теплообміну із природною конвекцією відбиті в [12]. Виявлено визначальний вплив температури на дрейф потужності магнетрона.

Можливості вдосконалювання

СПО розглядаються в [13]. Показано, що зменшення товщини ребра з 0,6 мм до 0,5 мм приводить до зниження ваги на $16,7 \%$ і інтенсифікації теплообміну. Однак дані поширюються на магнетрони, які працюють у складі домашніх мікрохвильових печей. У зв'язку 3 доцільністю переходу на СРО при проектуванні промислових установок, виникає необхідність розрахунку коефіцієнта тепловіддачі від поверхні анодного блоку до теплоносія. При організації рідинного охолодження анодного блоку теплоносій циркулює в кільцевому каналі. В [14] розрахунково-аналітичним методом визначена ефективність інтенсифікації тепловіддачі в кільцевому каналі при центральному теплопідводі. У той же час у даній роботі не враховується закручування потоку усередині кільцевого каналу. В [15] експериментальним шляхом отримано, що при використанні інтенсифікаторів різної форми на опуклій поверхні, що обігрівається, спостерігалося значне збільшення ефективності знімання теплоти. Коефіцієнт тепловіддачі в 1,8 рази вище, ніж для гладких кільцевих каналів. Це говорить про необхідність коректного підбора розрахункових формул, що відображають реальні умови протікання теплообмінних процесів. Було виявлено [16], що, хоча існують різні залежності для визначення коефіцієнта тепловіддачі в кільцевих каналах, область їхнього застосування недостатньо добре узгоджується 3 умовами тепловіддачі в сорочці охолодження магнетронів. Все це дозволяє затверджувати, що доцільно замінити СПО на СРО для промислових мікрохвильових установок. Основним завданням модернізації системи охолодження $\epsilon$ проведення дослідження теплообміну в кільцевому каналі сорочки охолодження анодного блоку й оцінка працездатності СРО.

\section{3. Матеріали й методи дослідження теплообміну в сорочці охолодження анодного блоку}

Для організації тепловідвода від поверхні за допомогою СРО потрібно замінити ребра СПО на поверхні анодного блоку, які встановлюються на магнетронах, що випускаються серійно, малої потужності, на сорочку рідинного охолодження. Для забезпечення безаварійної роботи СРО повинна бути постачена датчиками тиску, температури й витрати.

На рисунку 1 схематично представлена схема анодного блоку магнетрона, що випускається серійно, у первісному виді й після заміни СПО на СРО.

Робочі рідини (теплоносії) для заправлення СРО вибираються за наступними критеріями:

- робочий діапазон температур:

$20 \ldots+50^{\circ} \mathrm{C}$;

- рідина повинна бути нетоксична;

- відсутність хімічної активності;

- оптимальна вартість;

- доступність.

Відповідно до даних критеріїв, прийнято до розгляду застосування води й $54 \%$ водяного розчину етиленгліколю. Вода використовується для роботи при температурі навколишнього середовища від 2 до $50^{\circ} \mathrm{C}$, а водяний розчин етиленгліколю може застосовуватися при негативній температурі навколишнього середовища. 


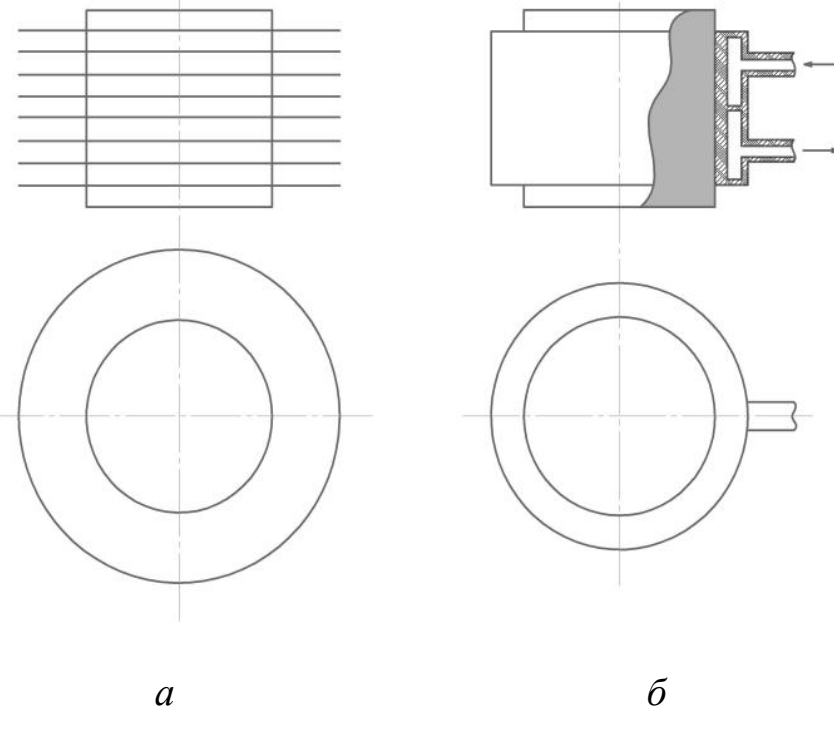

Рисунок 1 - Схема анодного блоку магнетрона з елементами системи охолодження: $a$-магнетрон з елементами СПО; $\sigma$-модернізований магнетрон зі СРО

Одним 3 визначальних питань при проведенні теплових розрахунків був вибір критеріального рівняння для розрахунку коефіцієнта тепловіддачі. Оскільки подібні канали дотепер не досліджувалися, виникла необхідність виготовлення експериментальної ділянки й проведення експериментів. Схема сорочки охолодження відповідала рис. 1, б. Виміри температур проводилися на вході й виході каналу за допомогою термопар хромельалюмель ТП.ХА $\left({ }^{\circ} \mathrm{C}\right)$, призначені для контролю температури рідких середовищ. Також вимірялася температура поверхні анодного блоку в трьох точках, дані по яких потім усереднювалися. Характеристики каналу наступні: більший діаметр $\mathrm{D}_{\mathrm{z}}=0,072 \mathrm{м}$; менший $\mathrm{d}=0,052 \mathrm{м}$; довжина $\mathrm{h}_{\mathrm{z}}=0,04$ м. Діапазон зміни температури теплоносія $\mathrm{t}=50 \ldots 100{ }^{\circ} \mathrm{C}$; об'ємна витрата теплоносія $\mathrm{G}=1,5 \cdot 10^{-4} \ldots 2,5 \cdot 10^{-4} \mathrm{~m}^{3} / \mathrm{c}$.

СРО заправляється теплоносієм перед початком роботи мікрохвильової установки. Після закінчення заправлення система автоматики сигналізуе про готовність магнетронів до роботи. Після виходу установки в режим, про що сигналізують індикатори на панелі керування, пристрій може бути переведене в автономний режим роботи. Після закінчення роботи пристрою СРО автоматично відключається.

\section{4. Дослідження роботи системи рідинного охолодження анодного блоку магнетрона}

Метою даного розрахунку $\epsilon$ визначення температур теплоносія на вході й виході з умови гранично припустимої температури поверхні анодного блоку магнетрона. Розглядався магнетрон 3 вихідною потужністю 1,0 кВт. При цьому споживана потужність $\mathrm{N}_{\mathrm{m}}=1200$ Вт. Потужність, яку необхідно відвести від анодного блоку, $\mathrm{Q}=200$ Вт. Припустима температура поверхні анодного блоку $\mathrm{t}_{\mathrm{a}}=100^{\circ} \mathrm{C}$. Сорочка охолодження кріпиться безпосередньо на анодний блок Анодний блок i сорочка охолодження виготовлені з міді.

Важливим питанням $€$ оцінка термічних опорів теплопровідності контактних плям і повітряного зазору. Будь-які дві поверхні, що перебувають у контакті, незалежно від сили їхнього стиску, залишаються віддаленими друг від друга через їхні шорсткості. Газ, рідина, різні прокладки можуть заповнювати простір між поверхнями, забезпечуючи наявність між ними контактного теплового опору (КТО). Теплота від однієї з дотичних поверхонь до іншої в загальному випадку може передаватися теплопровідністю через плями контакту $R_{m}$ й теплопровідністю через повітряне середовище $R_{v}$. Повітряне середовище заповнює простір між виступами й шорсткостями контактуючих поверхонь. Сумарний термічний опір за результатами розрахунків $R_{\Sigma}=\frac{R_{v} \cdot R_{m}}{R_{v}+R_{m}}=8,9 \cdot 10^{-5}, \mathrm{M}^{2} \cdot{ }^{\circ} \mathrm{C} /$ Вт. Виходячи зі знайденого термічного опору, стрибок температур у місці контакту: $\Delta t=q \cdot R_{\Sigma}=0,27{ }^{\circ} \mathrm{C}$. Перепад температур у місці контакту виявився незначним, тому в подальших розрахунках контактний термічний опір можна не враховувати.

У результаті обробки експериментальних даних отримана емпірична залежність (1) для середнього коефіцієнта тепловіддачі в умовах змушеного руху рідини в кільцевому каналі. При охолодженні моделі анодного блоку спостерігалися в'язкістні й перехідні режими pyxy.

$$
N u=\frac{\alpha \cdot d_{z}}{\lambda_{\varkappa}}=0,22 \cdot P e^{0,38} \cdot R a^{0,1}\left(\frac{\operatorname{Pr}_{\mathscr{H}}}{\operatorname{Pr}_{c m}}\right)^{0,25},
$$

де $\mathrm{Ra}$ - число Ралея, що розраховується по еквівалентному діаметрі каналу; Ре - число Пекле. 
Запропонована залежність ураховує особливості руху рідини в сорочці охолодження, зокрема, закручування потоку приводить до інтенсифікації теплообміну.

Отримано, що коефіцієнт тепловіддачі дорівнює $\alpha=2718 \mathrm{BT} /\left(\mathrm{M}^{2} \cdot \mathrm{K}\right)$ при використанні води в якості теплоносія. При цьому швидкість теплоносія в кільцевому каналі становила $\mathrm{w}=0,09 \mathrm{~m} / \mathrm{c}$. Коефіцієнт теплопередачі 3 урахуванням термічного опору анодного блоку дорівнює $\mathrm{k}=2664 \mathrm{BT} /\left(\mathrm{m}^{2} \cdot{ }^{\circ} \mathrm{C}\right)$. Зміна температури води при проходженні через сорочку охолодження $\delta t=1,04{ }^{\circ} \mathrm{C}$, середня температура теплоносія $t_{g}=88,5{ }^{\circ} \mathrm{C}$. Тоді температура води на вході в сорочку охолодження складе $\mathrm{t}^{\prime}=88^{\circ} \mathrm{C}$, а на виході $-\mathrm{t}^{\prime}=89^{\circ} \mathrm{C}$. Зроблено висновок, що для нормальної роботи магнетрона температура води на вході в сорочку охолодження не повинна перевищувати $90{ }^{\circ} \mathrm{C}$.

При використанні $54 \%$ водяного розчину етиленгліколю як теплоносій коефіцієнт тепловіддачі дорівнює $\alpha=1282$ Вт/( $\left.\mathrm{M}^{2} \cdot \mathrm{K}\right)$. Зміна температури теплоносія при проходженні через сорочку охолодження $\delta t=1,2{ }^{\circ} \mathrm{C}, \quad$ коефіцієнт теплопередачі $\mathrm{k}=1270 \mathrm{BT} /\left(\mathrm{M}^{2} \cdot \mathrm{K}\right), \quad$ середня температура теплоносія $t_{g}=76^{\circ} \mathrm{C}$. Для нормальної роботи магнетрона температура водяного розчину етиленгліколю на вході в сорочку охолодження не повинна перевищувати $75^{\circ} \mathrm{C}$.

Розрахунки показали, що застосування води як теплоносій збільшує коефіцієнт тепловіддачі в 2,2 рази в порівнянні $354 \%$ водяним розчином етиленгліколю. Коефіцієнт теплопередачі з урахуванням термічного опору анодного блоку в 2,1 рази вище для води. Таким чином, застосування води в представляється кращим. Однак при негативних температурах навколишнього середовища рекомендується заправляти систему рідинного охолодження водяними розчинами етиленгліколю.

\section{5. Висновки}

1. Для забезпечення температурного режиму поверхні анодного блоку при тепловому потоці 200 Вт витрати рідини $1,5 \cdot 10^{-4}$ кг/с температура води на вході в сорочку охолодження температура води не повинна перевищувати $88^{\circ}$ $\mathrm{C}$, а водного розчину етиленгліколю - $75{ }^{\circ} \mathrm{C}$. Контактним термічним опором між поверхнями анодного блоку і сорочки охолодження при проведенні розрахунків можна знехтувати.
2. Коефіцієнт тепловіддачі при використанні води в якості теплоносія при швидкості w=0,09 м/с у кільцевому каналі, площею теплообмінної поверхні $\mathrm{F}=6,5 \cdot 10^{-3} \mathrm{~m}^{2}$, дорівнює $2718 \mathrm{BT} /\left(\mathrm{M}^{2} \cdot \mathrm{K}\right)$, що в 2,2 рази вище, ніж при використанні 54 \% водного розчину етиленгліколю. При цьому температура на виході з сорочки охолодження підвищиться на $1,04{ }^{\circ} \mathrm{C}$, а розчину етиленгліколю - на $1,2{ }^{\circ} \mathrm{C}$. Коефіцієнт теплопередачі з урахуванням термічного опору анодного блоку в 2,1 рази вище для води. Застосування розчинів етиленгліколю обгрунтовано в разі роботи СРО при негативних температурах.

\section{Література}

1. Okeke C., Abioye A. E., Omosun Y. Microwave heating application in food processing // IOSR Journal of Electrical and Electronics Engineering. 2014. Vol. 9 (4). P. 29-34.

2. Abrication of Metal-Ceramic Functionally Graded Materials by Microwave Sintering / Bykov Yu. V., Egorov S. V., Eremeev A. G. etc. // Inorganic Materials: Applied Research. 2012. Vol. 3, Issue 3. P. 261-269.

3. El-Naggar S. M., Mikhaiel A. A. Disinfestation of stored wheat grain and flour using gamma rays and microwave heating // Journal of Stored Products Research, 2011. Vol.47, Iss.3. P. 191-196. 4. Potentials of Microwave Heating Technology for Select Food Processing Applications - a Brief Overview and Update / Puligundla P., Abdullah S. A., Choi W., Jun S., Oh S. E., Ko S. // Food Process Technolgy. 2013. Vol. 4, Issue 11. P. 2-9.

5. Микроволновая энергия, как фактор интенсификации тепломассопереноса и формирования полиэкстракта / Бурдо О.Г., Сиротюк И.В., Альхури Ю., Левтринская Ю.О. // Problemele energeticii regionale. 2016. Vol.1 (36) P. 59-71.

6. Arun S. Mujumdar. Handbook of Industrial Drying. 4th Edition - CRC Press. Taylor Francis Group. 2014. 1348 p.

7. Бюджетные генераторы для микроволновых плазмотронов / Тихонов В. Н., Иванов И. А., Крюков А. Е., Тихонов А. В. // Прикладная физика. 2015. № 5. С. 102-106.

8. Pozar D. M. Microwave Engineering - 4-rd edition. - N.Y.: Wiley. 2012. 756 p.

9. Alan Wall. The Radar System - Technical Principles In book: Radar and ARPA Manual. 2014. Published by Elsevier Ltd. P.29-137

10. В. И. Азаренков, А. С. Куценко. Методика и алгоритм инженерного расчета темпе- 
ратурного режима радиоэлектронной аппаратуры // Вісник національного технічного університету ХПІ. 2013. №2 (976). С. 22-28.

11. Г.И. Чурюмов, А.И. Экезли. Моделирование частотных характеристик магнетрона с двумя выводами энергии // Прикладная радиоэлектроника. 2012. Том 11, № 1. С. 63-71.

12. Yong-Soo Lee, Jong-Soo Lee. A study on the cooling system of low power magnetron by using the natural convection heat transfer // 4th IEEE International Conference on Vacuum Electronics. 2003. P. 134-135.

13. Dong Ho Park, Eung Ryeol Seo, Myoung Keun Kwon, Chang Seon Lee. A study on thermal fluid flow of magnetron cooling for microwave oven // Journal of Mechanical Science and Technology April 2019. Vol. 33, Issue 4, P. 1915-1923
14. В. П. Александренков. Исследование эффективности интенсификации теплоотдачи в кольцевом канале при центральном теплоподводе // Вестник МГТУ им. Н. Э. Баумана. Сер. Машиностроение. 2012. Vol. 4. С. 43-50.

15. Исследование теплоотдачи и гидравлического сопротивления в кольцевом канале с интенсификаторами теплообмена / Болтенко Э.А., Варава А.Н., Дедов А.В., Захаренков А.В., Комов А.Т., Малаховский С.А. // Теплоэнергетика. 2015. Vol. 3. С. 22-28.

16. J. Dirker, Josua $\mathbf{P}$ Meyer. Convective Heat Transfer Coefficients in Concentric Annuli Heat Transfer Engineering. March 2005. Vol. 26, Issue 2, P. 38-44.

Отримана в редакції 28.04.2019, прийнята до друку 07.06.2019

\title{
Modernization of cooling system of magnetrons of small power
}

\author{
I. Boshkova ${ }^{1 凶}$, A. Titlov $^{1}$, N. Volgusheva ${ }^{1}$, N. Kolesnichnko ${ }^{2}$, T. Sahala \\ ${ }^{1}$ Odessa National Academy of Food Technologies, 112 Kanatna str, Odesa, 65039, Ukraine \\ ${ }^{2}$ Odessa Military Academy, Fontanskaya road, 10, Odessa, 65000, Ukraine \\ $\triangle$ e-mail: boshkova.irina@gmail.com
}

The article of providing the thermal regime of the anode block of the magnetron by replacing the air cooling system with the liquid cooling system is considered. It is claimed that the liquid cooling system is most suitable for magnetrons, which currently provide an air cooling system, but are not designed for long-term work in the composition of industrial microwave device. The organization of the liquid cooling system will allow the magnetron to work for a long time without overheating and under favorable conditions, in which the clogging of the heat transfer surface by particles and dust and the overheating of the surface of the anode block are excluded. The main element of the developed liquid cooling system is a cooling jacket, which is a circular channel made of heat-conducting material. The cooling jacket is fastened directly to the anode block, the degree of compression of the surfaces and the thickness of the air gap should provide a minimum total thermal resistance. An empirical dependence was obtained to determine the heat transfer coefficients, which reflects the fact that viscous and viscosity-gravity modes of motion are rational when cooling the anode block. The main thermal characteristics of the cooling process, including the heat transfer coefficient, the change in the coolant temperature, the maximum permissible inlet temperature, are determined. The calculations were performed for two types of coolants: water and $54 \%$ ethylene glycol aqueous solution. The application of this circuit solution and the choice of rational calculation modes allows to solve the problem of increasing the efficiency of production and reliability of microwave technology.

Key words: anode block, magnetron, contact thermal resistance, water, ethylene glycol, thermal regime

\section{References}

1. Okeke, C., Abioye, A. E., Omosun, Y. (2014).

Microwave heating application in food processing.
IOSR Journal of Electrical and Electronics Engineering, 9 (4), 29-34. Doi: https://doi.org/10. 9790/1676-09422934

2. Bykov, Yu. V., Egorov, S. V., Eremeev, A. G. 
(2012). Fabrication of Metal-Ceramic Functionally Graded Materials by Microwave Sintering. Inorganic Materials: Applied Research, 3(3), 261-269. Doi: https://doi.org/10.1134/s2075113312030057

3. El-Naggar, S. M., Mikhaiel, A. A. (2011). Disinfestation of stored wheat grain and flour using gamma rays and microwave heating. Journal of Stored Products Research, 47 (3), 191-196. Doi: https://doi.org/10.1016/j.jspr.2010.11.004

4. Puligundla, P., Abdullah, S. A., Choi, W., Jun, S., Oh, S. E., Ko, S. (2013.) Potentials of Microwave Heating Technology for Select Food Processing Applications - a Brief Overview and Update. Food Process Technolgy, 4(11), 2-9. Doi: https://doi.org/10.4172/2157-7110.1000278

5. Burdo, O.G., Sirotyuk, I.V., Alkhuri, Yu., Levtrinskaya, Yu.O. (2016). Mikrovolnovaya energiya, kak faktor intensifikatsii teplomassoperenosa i formirovaniya poliekstrakta (Microwave energy as a factor in the intensification of heat and mass transfer and the formation of a polyextract). Problemele energeticii regionale, 1 (36), 59-71.

6. Mujumdar, Arun S. (2014). Handbook of Industrial Drying. 4th Edition - CRC Press. Taylor Francis Group, 1348 p.

7. Tikhonov, V. N., Ivanov, I. A., Kryukov, A. E., Tikhonov, A. V. (2015). Low-cost generators for microwave plasma torches. Applied Physics, 5, 102106.

8. Pozar, D. M. (2012). Microwave Engineering 4-rd edition. - N.Y.: Wiley. 756 p.

9. Bole, A., Wall, A., Norris, A. (2014). The Radar System - Technical Principles In book: Radar and ARPA Manual. Published by Elsevier Ltd, 29-137. Doi: https://doi.org/10.1016/b978-0-08-0977522.00002-7
10. Azarenkov, B. I., Kutsenko, A. S. (2013). Method and algorithm of engineering calculation of temperature mode of radio electronic equipment. Visnyk natsionalnoho tekhnichnoho universytetu KhPI, 2 (976), 22-28.

11. Churyumov, G.I., Ekezli, A.I. (2012). Modeling of frequency characteristics of magnetron with two energy conclusions. Applied Radio Electronics. 11 (1), 63-71.

12. Lee, Yong-Soo, Lee, Jong-Soo. (2003). A study on the cooling system of low power magnetron by using the natural convection heat transfer. 4th IEEE International Conference on Vacuum Electronics, Seoul, South Korea, 134-135. Doi: https://doi.org/10.1109/ivec.2003.1286123

13. Dong Ho Park, Eung Ryeol Seo, Myoung Keun Kwon, Chang Seon Lee (2019). A study on thermal fluid flow of magnetron cooling for microwave oven. Journal of Mechanical Science and Technology, 33 (4), 1915-1923. Doi: https://doi.org/10.1007/s12206-019-0342-x

14. Aleksandrenkov, V. P. (2012). Investigation of the efficiency of heat transfer intensification in the annular channel at the central heat supply. Vestnik MGTU im. N. E. Baumana. Ser. Mashinostroyeniye, 4, 43-50.

15. Boltenko , E.A., Varava, A.N., Dedov, A.V., Zakharenkov, A.V., Komov, A.T., Malakhovskii, S.A. (2015). Investigation of heat transfer and pressure drop in an annular channel with heat transfer intensifiers. Thermal Engineering, 62 (3), 177-182.

16. Dirker, J., Meyer, Josua P. (2005). Convective Heat Transfer Coefficients in Concentric Annuli. Heat Transfer Engineering, 26(2), 38-44. Doi: https://doi.org/10.1080/01457630590897097. 